\title{
The Grain-size Patchiness of Braided Gravel-Bed Streams - example of the Urumqi River (northeast Tian Shan, China)
}

\author{
L. Guerit ${ }^{1}$, L. Barrier ${ }^{1}$, C. Narteau ${ }^{1}$, F. Métivier ${ }^{1}$, Y. Liu ${ }^{2,3}$, E. Lajeunesse ${ }^{1}$, E. Gayer ${ }^{1}$, P. Meunier ${ }^{4}$, L. Malverti ${ }^{1}$, and \\ B. $\mathbf{Y e}^{2}$ \\ ${ }^{1}$ Institut de Physique du Globe de Paris, Sorbonne Paris Cité, Université Paris Diderot, UMR CNRS 7154, Paris, France \\ ${ }^{2}$ The States Key laboratory of Cryospheric Science, Cold and Arid Region Environmental and Engineering and Research \\ Institute, Chinese Academy of Sciences, Lanzhou, China \\ ${ }^{3}$ Key Laboratory of Water Environment and Resource, Tianjin Normal University, Tianjin, China \\ ${ }^{4}$ École Normale Supérieure, Département de Géologie, UMR CNRS 8538, Paris, France
}

Correspondence to: L. Guerit (guerit@ipgp.fr)

Received: 1 May 2013 - Revised: 23 May 2013 - Accepted: 1 July 2013 - Published: 11 February 2014

\begin{abstract}
In gravel-bed rivers, sediments are often sorted into patches of different grain-sizes, but in braided streams, the link between this sorting and the channel morphosedimentary elements is still unclear. In this study, the size of the bed sediment in the shallow braided gravel-bed Urumqi River is characterized by surface-count and volumetric sampling methods. Three morpho-sedimentary elements are identified in the active threads of the river: chutes at flow constrictions, which pass downstream to anabranches and bars at flow expansions. The surface and surface-layer grainsize distributions of these three elements show that they correspond to only two kinds of grain-size patches: (1) coarsegrained chutes, coarser than the bulk river bed, and (2) finergrained anabranches and bars, consistent with the bulk river bed. In cross-section, the chute patches are composed of one coarse-grained top layer, which can be interpreted as a local armour layer overlying finer deposits. In contrast, the grain size of the bar-anabranch patches is finer and much more homogeneous in depth than the chute patches. Those patches, which are features of lateral and vertical sorting associated to the transport dynamics that build braided patterns, may be typical of active threads in shallow gravel-bed rivers and should be considered in future works on sorting processes and their geomorphologic and stratigraphic results.
\end{abstract}

\section{Introduction}

Geomorphologists and sedimentologists observed early on that, at a local scale, the grain-size organization of gravel-bed rivers is not homogeneous in space but sorted into patches, which can be defined as areas of similar grain sizes (e.g., Leopold et al., 1964; Bluck, 1971, 1976; Lisle and Madej, 1992). This patchiness is of fundamental importance for many hydro-sedimentary processes within rivers as the grainsize distribution affects bed roughness and availability of the different size fractions for transport (Ferguson et al., 1989; Garcia et al., 1999). Hence, grain-size patches influence both the shear stress field (Naot, 1993; Robert et al., 1992; Wilcock and McArdell, 1993) and bedload transport within channels (Bluck, 1987; Paola and Seal, 1995; vericat et al., 2008), but also downstream fining (Bluck, 1987; Seal and Paola, 1995; Sambrook Smith and Ferguson, 1996), stratigraphic record (Steel and Thompson, 1983; Nemec and Postma, 1993; Lunt and Bridge, 2004), and aquatic ecology (Wiens, 1976; Kondolf and Wolman, 1993). Yet, it is difficult to make sense of grain-size organization in gravel-bed rivers. For single-thread streams, it has long been known that the local grain-size sorting is closely related to the channel morpho-sedimentary elements (e.g., Leopold et al., 1964; Bluck, 1971; Milne, 1982; Lisle and Madej, 1992). In contrast, this relationship is still unclear in multi-thread streams like braided rivers. Therefore, it is important to provide new constraints on the location and characteristics of sediment sorting in such rivers. 

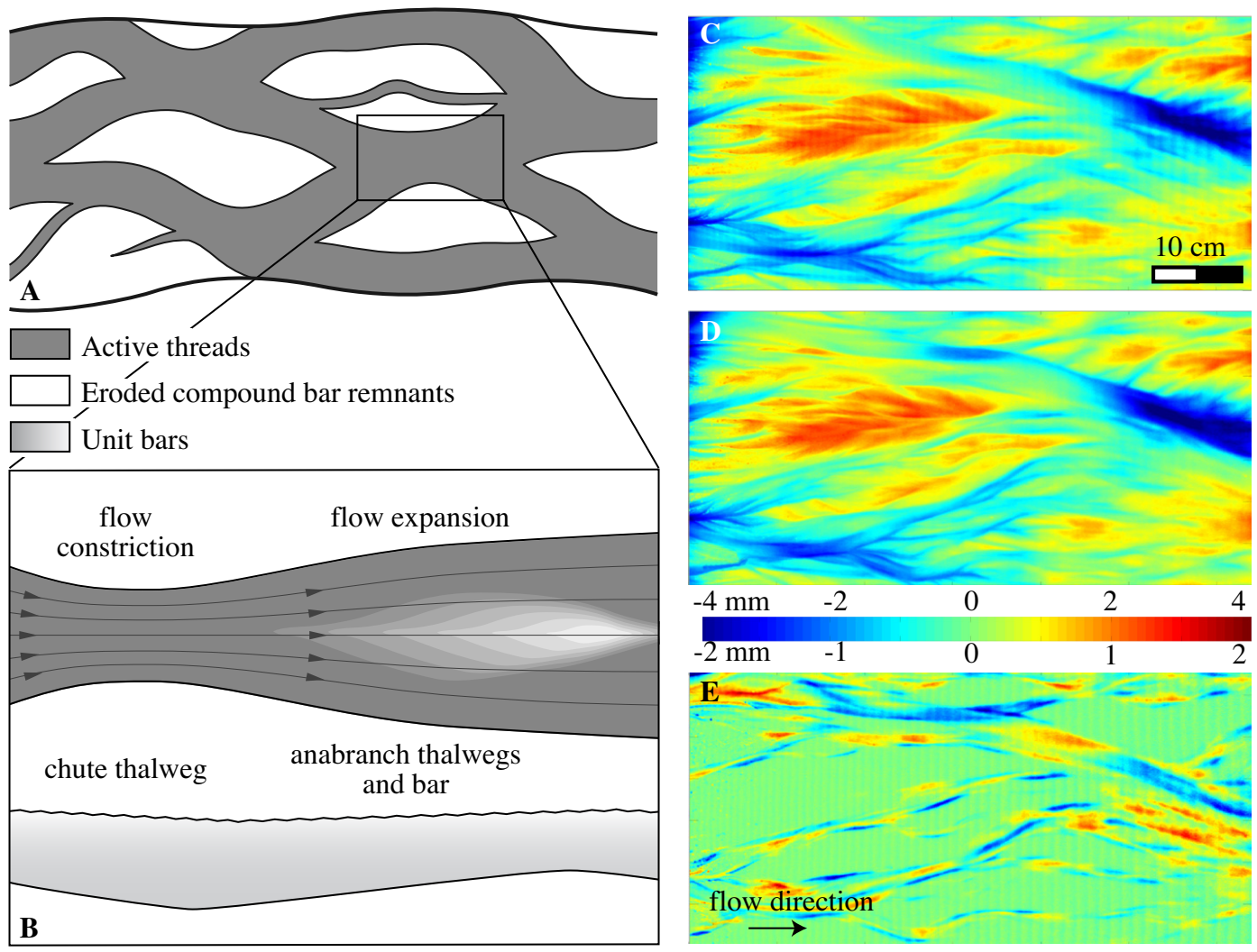

Fig. 1. Morphological features of the braided gravel-bed rivers at the scale of their (a) compound and (b) unitary morpho-sedimentary elements (in map view and longitudinal section). Note that (a) is considered to be exclusively composed of (b). (c) and (d) Five minutes apart topography scans of the bed of an experimental braided river (modified from Limare et al., 2011). (e) Elevation differential map between the two previous topographies. Areas of erosion (in blue) and deposition (in yellow and red) alternate within the active threads, which surround stable areas of the braidplain (in green). This illustrates that sediment transport occurs in active threads only.

At the reach scale, braided streams are characterized by active threads separated by dry areas corresponding to remnants of compound bars (Fig. 1a) (e.g., Bluck, 1974; Ashmore, 1982; Church and Jones, 1982). Within these threads, sequences of three morpho-sedimentary elements are observed: chute thalwegs at flow constrictions, and anabranch thalwegs and unit bars at flow expansions (Fig. 1b). Qualitatively, the chutes are characterized by a steep and narrow concave (curved inward) morphology and by coarse grainsize. The anabranches are also concave but look flatter and finer-grained. The bars, which are lobate tabular bedforms without avalanche slip faces at their margins, have a flat, large and convex (curved outward) morphology and generally exhibit the finest grain-size. These sequences are considered as the building blocks of gravelly braided river systems (e.g., Smith, 1974; Ashmore, 1982; Southard et al., 1984; Ashworth, 1996; Ashmore, 2013). These building blocks are equivalent to the dynamical features observed in natural or experimental streams. Based on topographic measurements through time, the bed evolution of braided rivers clearly shows that braidplains are made up of two primary dynamical features: zones of erosion and scour at flow convergences, which correspond to chutes, followed by zones of deposition, which resemble unit bars associated with small withinchannel anabranch thalwegs that eventually evolve into distinct threads with time (Lane et al., 2003; Wheaton et al., 2010; Ashmore et al., 2011; Limare et al., 2011) (Fig. 1c, $1 \mathrm{~d}$ and 1e). On the other hand, despite their significant areal extension, the role of compound bar remnants in the dynamics of braids has never been put forward either by physical experiments (Métivier and Meunier, 2003; Ashmore et al., 2011; Limare et al., 2011) or by mechanical analyzes of flow stability ( Métivier and Barrier, 2012, and references therein). Excluding works carried out on these compound structures only (Bluck, 1974; Ashworth and Ferguson, 1986; Lunt and Bridge, 2004), grain-size studies in multi-thread streams have mainly focused on the downstream sorting that occurs on unit bars (Smith, 1974; Hein and Walker, 1977; Bluck, 1982; Ashworth et al., 1992a, b; Hassan, 2005; Rice and Church, 2010). Comparatively, only a few works with limited data sets have compared bar and thalweg grain sizes (Smith, 1974; Ashworth et al., 1992a; Laronne et al., 1994; Laronne and Shlomi, 2007). 

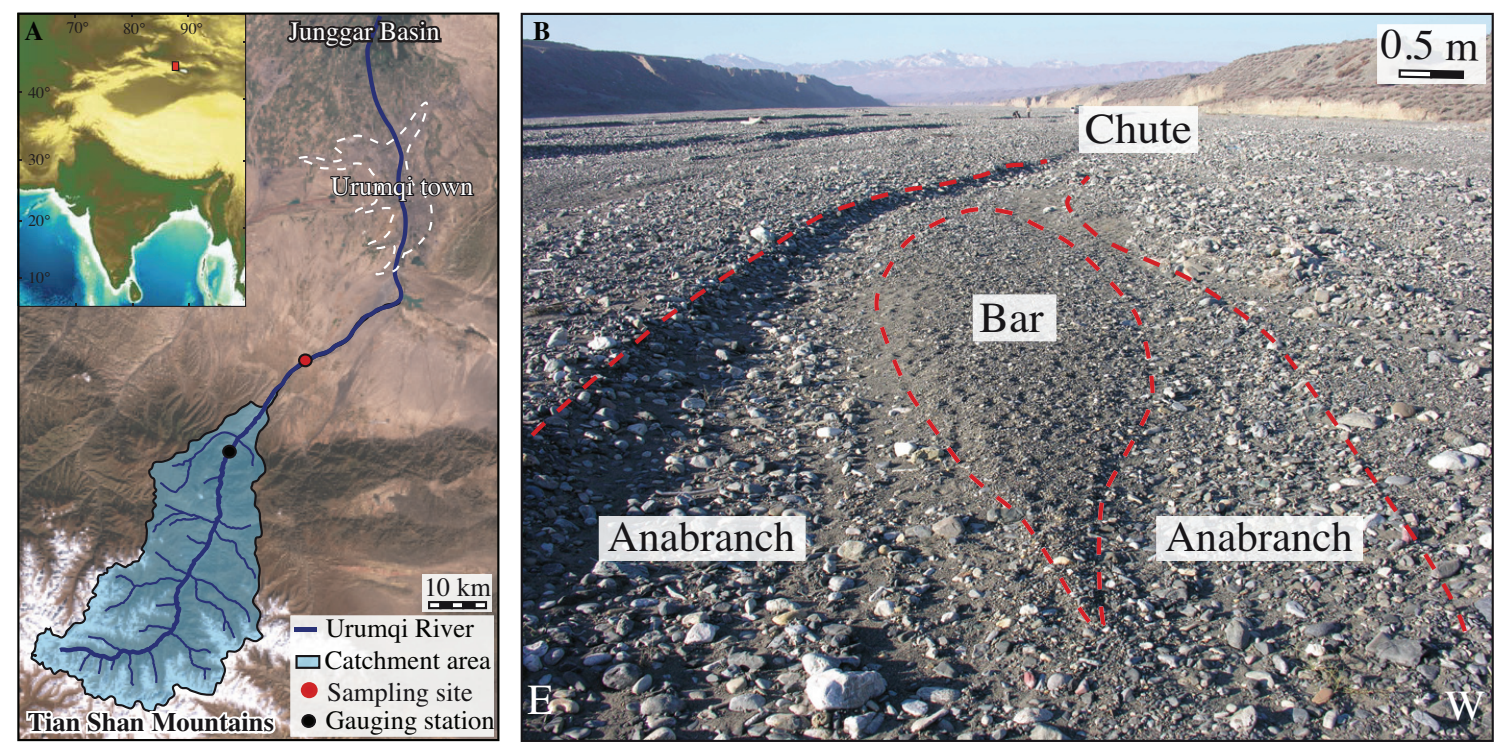

Fig. 2. (a) Location of the sampling site (red dot) along the Urumqi River, and (b) example of the three unitary morpho-sedimentary elements of the river bed. Flow is from South to North.

To complete these works, a field study was performed on the Urumqi River, a shallow gravelly braided river in China. During two field surveys, the grain-size distributions (GSDs) of the river bed, and of the surface material and of the surface layer of the morpho-sedimentary elements typically found into the active threads were characterized by volumetric samplings and surface counts. This article presents the grain-size analysis carried out to investigate (1) the link between the grain-size patchiness and the morpho-sedimentary elements, and (2) the relationship between this grain-size patchiness and the bulk GSD of the river bed. Only two types of grainsize patches are identified, which are features of lateral and vertical sorting associated with transport processes that build braided patterns in shallow gravel-bed rivers.

\section{The Urumqi River at the sampling site}

The Urumqi River is a shallow (up to one meter-deep) braided gravel-bed river that flows on the northern side of the Tian Shan Mountains in China, near the town of Urumqi (Fig. 2). This river rises at the front of a glacier at an elevation of $3600 \mathrm{~m}$ and runs northwards to the Junggar basin, where it dies out into a desert at an elevation of $1100 \mathrm{~m}$. Our sampling site is located about $10 \mathrm{~km}$ downstream of the mountain topographic front (Fig. 2), where the Urumqi River braids within an alluvial valley cut down into the deposits of a former alluvial fan (Zhou et al., 2002). At this location, the mean slope is 0.02 , the catchment area is around $1000 \mathrm{~km}^{2}$, and runoff is mainly regenerated by summer rains and snow or ice melting. Hence, the Urumqi River mostly flows from May to September. Monthly measurements over a 22-year time period reveal a mean annual discharge of $7.47 \mathrm{~m}^{3} \mathrm{~s}^{-1}$ at a gauging station located few kilometers upstream of the sampling site (Fig. 2 and Zhou et al., 1999). The total sedimentary load is about $1-210^{8} \mathrm{~kg} \mathrm{yr}^{-1}$ (45\% as dissolved load, $35 \%$ as suspended load and $17 \%$ as bed load) (Liu et al., 2008, 2011). Outside of the high flow season, the river is almost completely dry and it becomes possible to measure the bed material at many locations.

This study focuses on the elements identified in the recently active threads (chutes, anabranches and unit bars, Fig. 2b), which correspond to unit structures formed by active sediment transport under high to moderate flow. Others structures, such as compound bar remnants were not considered.

\section{Data acquisition and analysis}

\subsection{Sampling strategy}

At the sampling site, a three-step strategy was implemented, in order to sample the bulk GSD of the river bed, as well as the surface and the surface-layer GSDs of the morpho-sedimentary elements defined previously. In gravelbed rivers, the surface layer is defined as the deposits lying from the surface down to a depth corresponding to the size of the largest clasts (usually one or two $\mathrm{D}_{90}$ ) (Sutherland, 1987; Church et al., 1987). In the Urumqi River, the $\mathrm{D}_{90}$ is around $10 \mathrm{~cm}$, so the surface layer is defined as the sediments from the top of the river bed down to $20 \mathrm{~cm}$. The subsurface extends below these surface deposits.

To characterize these layers, two granulometric sampling techniques were used: the surface-count (Wolman grid-bynumber) and the volumetric (sieve-by-weight) methods. The 
first one considers the grains lying on the top of the river bed (Wolman, 1954). It is classically used to sample surface GSDs. The second method considers a volume of sediments. It is usually implemented to sample subsurface GSDs.

For surface counts, a grid was layered over the surface to be sampled, with points located every $20 \mathrm{~cm}\left(\simeq 2 \mathrm{D}_{90}\right)$ in order to avoid sampling the same grain twice. The intermediate (b-axis) diameter of the grains under the knots was measured, as it permits a comparison with the volumetric data (Kellerhalls ans Bray, 1971; Church et al., 1987; Bunte and Abt, 2001). In addition, only grains with a b-axis larger than $8 \mathrm{~mm}$ were considered to reduce the size measurement uncertainties associated with this surface methodology (Kellerhalls ans Bray, 1971; Church et al., 1987; Bunte and Abt, 2001). Eventually, it is recommended to collect 100 to 400 grain measurements to have a representative surface-count sample with the diameters defined from \pm 10 to $5 \%$ (Church et al., 1987; Diplas and Fripp, 1992; Rice and Church, 1996).

For the volumetric samples, the sediments were excavated and sieved using mesh sizes ranging from $25.6 \mathrm{~cm}$ to $63 \mu \mathrm{m}$, each mesh size being twice the previous one. The grains retained on each sieve were then weighed in order to obtain a mass for a given mean diameter, which is considered to be the mean b-axis of the clasts. To be consistent with the surface-count samples, only grains larger than $8 \mathrm{~mm}$ were taken into account. The depth of the excavated volume must be at least $2 \mathrm{D}_{90}$ to assure that large grains can be sampled, and its area must be calculated in order to fulfill the accuracy criteria defined by Church et al. (1987). Ideally, these authors propose that the biggest grain of a volumetric sample does not represent more than $0.1 \%$ in weight of the total sample. In that case, grain-size fractions are determined with a $0.1 \%$ precision. In practice, this precision is never achieved because of the excessively large volume needed, and because the within site variability by far exceeds this limit for gravelbed streams. Therefore, less stringent precisions are usually adopted. In this study, accuracy values vary from $0.5 \%$, a quite stringent condition, up to more loose accuracy of $5 \%$.

First, the bulk GSD, that corresponds to the subsurface distribution of the river bed, was characterized by this volumetric technique. A deep trench of $7 \times 1.2 \times 1 \mathrm{~m}^{3}$ was dug into the river bed (Fig. 3). In order to get the subsurface grains only, the surface layer $(\simeq 20 \mathrm{~cm})$ was removed. Excluding the sand fraction, which represents about $25 \%$ of the sample, about $8660 \mathrm{~kg}$ of grains larger than $8 \mathrm{~mm}$ were finally sieved and weighed (Table 1). According to Church et al. (1987), this sample falls around the $0.5 \%$ precision.

Then, the surface GSDs of the morpho-sedimentary elements were characterized by surface counts. Eight chutes, eight anabranches and nine bars were sampled with grids layered at their surface (Fig. 3b). Depending on their areal extension (i.e. a few square metres), 38 to 471 clasts were measured on each element. These individual samples can be then added, in order to obtain one larger sample with more than 500 grains for each kind of element (Table 1).
Finally, the surface-layer GSDs of the morphosedimentary elements were characterized by the volumetric technique. Among the elements sampled by surface counts, five chutes, five anabranches and five bars were sampled by excavating a series of shallow trenches without removing the first layer of sediments, each $1.5 \times 1 \times 0.2 \mathrm{~m}^{3}$ in area (Fig. 3c). After the removal of the sand fraction, these small samples weight about $300-400 \mathrm{~kg}$ and fall in a $5 \%$ precision range (Church et al., 1987) (Table 1). These individual samples can also be added to obtain three large average samples weighting more than $1600 \mathrm{~kg}$ and falling in a $0.5 \%$ precision range (Church et al., 1987) (Table 1). One can notice that this kind of sampling is new because the surface layer is basically never sampled. However, this is the layer of sediments accessible for bed load transport in a gravel-bed river. In addition, it makes the connection between the hydraulic processes of sorting and the bulk deposition, and therefore, links the morphologic with sedimentologic patterns

\subsection{Sample analysis}

The grain sizes were normalized using the $\phi$-scale $\left(\log _{2}\right.$ based) and fitted by the normal law, as it characterizes distributions through only two parameters: the mean and the standard deviation. The simplest way to assess the accuracy of the normal fit is to use quantile-quantile plots (Q-Q plots), which compare the quantiles of two distributions to determine whether they are equivalent or significantly different. In practice, the mean diameter $D_{50}$ and the standard deviation $\sigma$ of each $\phi$-normalized GSDs were used to generate normal distributions. The $\mathrm{Q}_{10}$ to $\mathrm{Q}_{100}$ quantiles of these normal distributions were then compared to the quantiles of the sample distributions (Fig. 4a). For the volumetric samples, in order to avoid interpolation between the measurements, the quantiles correspond to those defined by the points issued from the discrete CDF (Fig. 4b). In each case, plotted points are quite well aligned on the $x=y$ line, implying that the compared distributions are equal. Thus, normal distributions can safely be used to analyze the data presented here and this allows a statistical investigation.

For the surface-count samples, Monte Carlo simulations were used to evaluate the error bars of the sample parameters, $D_{50}$ and $\sigma$ (Table 1). For each sample, 10000 normal distributions were generated using the same number of grains, $D_{50}$ and $\sigma$. The real parameters of each generated distributions were calculated to estimate the potential variation of each sample. This analysis is directly applicable on surface-count samples but not on the volumetric ones because they give no information about the diameter of individual grain in each sieve. Consequently, $D_{50}$ uncertainties for volumetric samples were calculated according to Church et al. (1987) (Table 1). However, it is not possible to evaluate the uncertainties associated to standard deviation of these samples without a precise knowledge of sediment shape and density. 

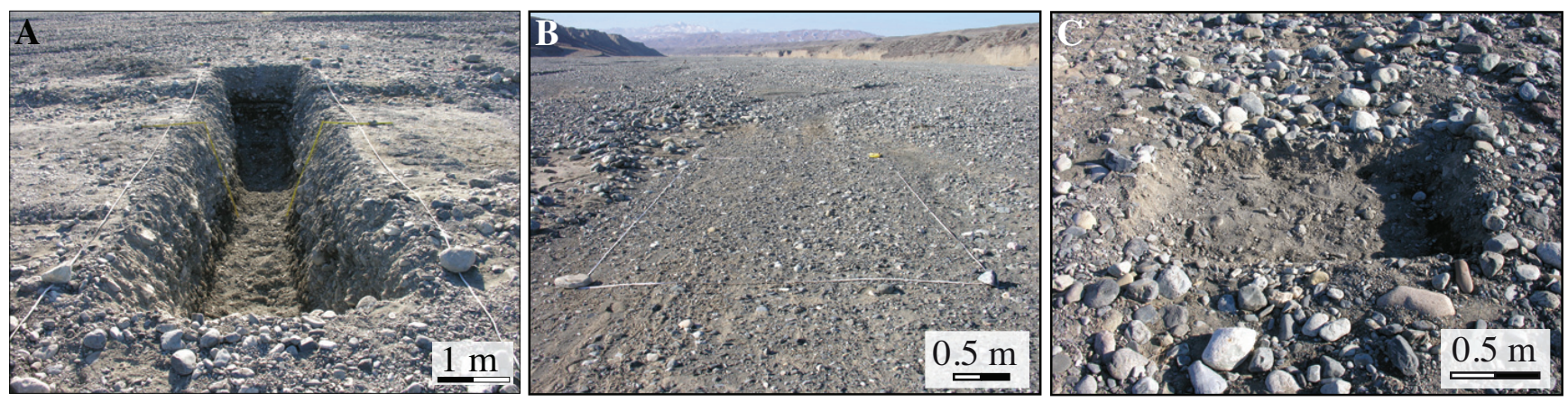

Fig. 3. (a) View of the deep trench dug to sample the Urumqi river bed. This trench is $7 \mathrm{~m}$ long, $1.2 \mathrm{~m}$ large and $0.8 \mathrm{~m}$ deep after removing the surface layer $(\sim 20 \mathrm{~cm})$. (b) and (c) Examples of a grid and a shallow trench used to sample single morpho-sedimentary elements. The grid presented here is $4 \mathrm{~m}$ long and $3 \mathrm{~m}$ large, whereas the trench is $1.5 \mathrm{~m}$ long, $1 \mathrm{~m}$ large and $0.2 \mathrm{~m}$ deep.
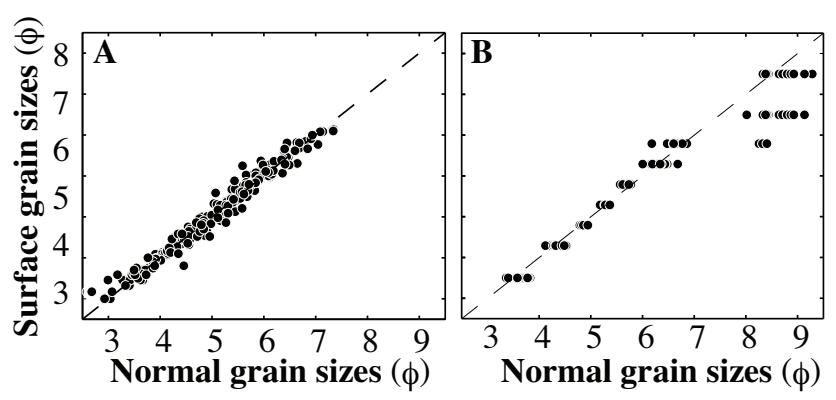

Fig. 4. Q-Q plots used to assess the accuracy of the normal fit of the $\phi$-transformed grain-size distributions. (a) Comparison of the 10th, 20 th, etc. quantiles of the 25 surface grain-size distributions to their equivalent normal distributions. (b) Comparison of the quantiles of the 15 surface-layer grain-size distributions to their equivalent normal distributions. Plotted points are quite aligned on the $x=y$ line, implying that all the $\phi$-transformed samples can be fitted by a normal distribution.

Finally, ANOVA tests were performed to analyze the variability in GSDs with respect to the unitary morphosedimentary element (Tables 2 and 3). These tests require that the samples are normally distributed and have equal variance, and therefore are based on the $\phi$-transformed distributions. ANOVA tests determine whether at least two groups of samples come from the same population or from different populations based on the analysis of their variance. The ratio $F$ of the variability within and between the different groups is calculated and compared to theoretical $F$-values. The tests were based on the null hypothesis $\mathrm{H}_{0}$ : the samples come from the same population of grains. This hypothesis is rejected if the parameter $F$ is higher than the acceptable values $\mathrm{F}_{95}$ or $\mathrm{F}_{99}$ at a level of significance of $95 \%$ and $99 \%$, respectively.

\section{Granulometry of the river bed}

The data collected were analyzed in order to (1) characterize a local bulk GSD of the river bed, (2) determine whether the morpho-sedimentary elements correspond to grain-size patches, and (3) investigate the relationships between these grain-size patches and the bulk GSD of the bed.

\subsection{Bulk distribution of the river bed}

First, the volumetric sample taken from the subsurface layer (from 0.2 to 1 meter-deep) of the deep trench was used to characterize a bulk GSD of the Urumqi river bed. This sample is unimodal with about $80 \%$ of pebbles, a mean diameter $D_{50}$ of $4.73 \phi(26.5 \mathrm{~mm})$, and a standard deviation $\sigma$ of 1.2 (Table 1). It is almost impossible to demonstrate whether this sample characterizes the whole bulk distribution of the river bed. However, it corresponds to a local bulk distribution taken near the studied elements and is considered in this study as the reference GSD for the river bed.

\subsection{Surface distributions of the morpho-sedimentary elements}

The surface-count samples from the 25 morpho-sedimentary elements (eight chutes, eight anabranches and nine bars) were compared to determine if these elements correspond to different grain-size patches or not. On average, the surface grain size of chutes is coarser than grain size of the anabranches and bars (Fig. 5a and Table 1). Indeed, each kind of element is characterized by a range of distributions, with a large overlap between the anabranch and bar grain sizes that are too close to be distinguished from one another. In contrast, the chute GSDs clearly fall on the right part of the graph and overlap very little with the other GSDs. For example, the $D_{50}$ of the anabranch and bar samples ranges from 4.00 to $5.14 \phi$, whereas the $D_{50}$ of the chutes ranges from 5.28 to $6.10 \phi$. In other words, the surface of the chutes is always coarser-grained than the surface of the anabranches and bars. The ANOVA tests support these observations by confirming that the chute GSDs are statistically different from the anabranch and bar GSDs, which constitute only one single population (Table 3). 
Table 1. Statistics of the GSDs. $D_{50}(\mathrm{~mm})$ is the mean diameter of the distributions, $D_{50}\left(\log _{2}\right)$ the mean diameter of the $\phi$-normalized distributions $\left(D_{50}\left(\log _{2}\right)=\log _{2}\left(D_{50}\right)(\mathrm{mm})\right)$, and $\Delta D_{50}$ the associated uncertainty. $\sigma$ is the standard deviation of the $\phi$-normalized distributions and $\Delta \sigma$ the associated uncertainty. Grain-size classes are from Wentworth (1922).

\begin{tabular}{|c|c|c|c|c|c|c|c|c|c|c|c|}
\hline & $\begin{array}{l}\text { Sample } \\
\text { type }\end{array}$ & $\begin{array}{l}\text { Sampling } \\
\text { method }\end{array}$ & $\begin{array}{l}\text { Sample size } \\
(\mathrm{D} \geq 8 \mathrm{~mm})\end{array}$ & $\begin{array}{c}\text { Pebble } \\
(\%)\end{array}$ & $\begin{array}{c}\text { Cobble } \\
(\%)\end{array}$ & $\begin{array}{c}\text { Boulder } \\
(\%)\end{array}$ & $\begin{array}{c}D_{50} \\
(\mathrm{~mm})\end{array}$ & $\begin{array}{c}D_{50} \\
\left(\log _{2}\right)\end{array}$ & $\begin{array}{c}\Delta D_{50} \\
( \pm)\end{array}$ & $\sigma$ & $\begin{array}{l}\Delta \sigma \\
( \pm)\end{array}$ \\
\hline & Bulk & Volume & $8660 \mathrm{~kg}$ & 78 & 21 & 1 & 26.5 & 4.73 & 0.2 & 1.2 & $\Delta$ \\
\hline \multirow{16}{*}{ 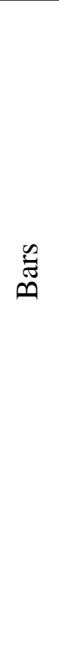 } & \multirow{9}{*}{ Surface } & \multirow{10}{*}{ Surface } & 53 grains & 96 & 4 & 0 & 17.2 & 4.10 & 0.3 & 0.9 & 0.2 \\
\hline & & & 42 grains & 86 & 14 & 0 & 24.8 & 4.63 & 0.6 & 0.9 & 0.4 \\
\hline & & & 38 grains & 89 & 11 & 0 & 15.6 & 4.00 & 0.7 & 1.1 & 0.5 \\
\hline & & & 36 grains & 92 & 8 & 0 & 26.9 & 4.75 & 0.5 & 0.8 & 0.3 \\
\hline & & & 41 grains & 98 & 2 & 0 & 17.2 & 4.10 & 0.5 & 0.8 & 0.3 \\
\hline & & & 36 grains & 97 & 3 & 0 & 20.3 & 4.34 & 0.6 & 0.8 & 0.3 \\
\hline & & & 99 grains & 77 & 23 & 0 & 31.8 & 4.99 & 0.4 & 1.1 & 0.3 \\
\hline & & & 153 grains & 95 & 5 & 0 & 24.6 & 4.62 & 0.3 & 0.8 & 0.2 \\
\hline & & & 225 grains & 85 & 15 & 0 & 25.7 & 4.68 & 0.2 & 1 & 0.2 \\
\hline & Total & & 723 grains & 89 & 11 & 0 & 24.2 & 4.59 & 0.1 & 1.0 & 0.1 \\
\hline & \multirow{5}{*}{ Surface layer } & \multirow{6}{*}{ Volume } & $330 \mathrm{~kg}$ & 84 & 16 & 0 & 24.2 & 4.59 & 0.2 & 1.0 & $\Delta$ \\
\hline & & & $280 \mathrm{~kg}$ & 86 & 14 & 0 & 20.0 & 4.33 & 0.2 & 1.2 & $\Delta$ \\
\hline & & & $340 \mathrm{~kg}$ & 87 & 13 & 0 & 24.9 & 4.64 & 0.2 & 0.9 & $\Delta$ \\
\hline & & & $320 \mathrm{~kg}$ & 85 & 15 & 0 & 23.1 & 4.53 & 0.2 & 1.0 & $\Delta$ \\
\hline & & & $352 \mathrm{~kg}$ & 77 & 23 & 0 & 29.1 & 4.86 & 0.2 & 1.1 & $\Delta$ \\
\hline & Total & & $1620 \mathrm{~kg}$ & 83 & 17 & 0 & 24.3 & 4.60 & 0.2 & 1.1 & $\Delta$ \\
\hline \multirow{15}{*}{ 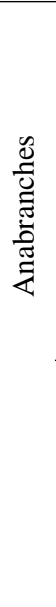 } & \multirow{9}{*}{ Surface } & \multirow{9}{*}{ Surface } & 93 grains & 76 & 24 & 0 & 34.3 & 5.10 & 0.3 & 1.1 & 0.2 \\
\hline & & & 65 grains & 66 & 34 & 0 & 34.5 & 5.11 & 0.4 & 1.0 & 0.4 \\
\hline & & & 44 grains & 80 & 20 & 0 & 22.1 & 4.46 & 0.6 & 1.1 & 0.4 \\
\hline & & & 94 grains & 89 & 11 & 0 & 25.7 & 4.68 & 0.3 & 0.9 & 0.3 \\
\hline & & & 80 grains & 90 & 10 & 0 & 28.9 & 4.85 & 0.4 & 1.0 & 0.3 \\
\hline & & & 48 grains & 85 & 15 & 0 & 17.6 & 4.14 & 0.6 & 1.1 & 0.5 \\
\hline & & & 149 grains & 76 & 24 & 0 & 35.3 & 5.14 & 0.4 & 1.2 & 0.2 \\
\hline & & & 431 grains & 85 & 15 & 0 & 27.2 & 4.76 & 0.2 & 1.0 & 0.1 \\
\hline & & & 1004 grains & 82 & 18 & 0 & 28.7 & 4.84 & 0.1 & 1.1 & 0.1 \\
\hline & \multirow{6}{*}{ Surface layer } & \multirow{6}{*}{ Volume } & $382 \mathrm{~kg}$ & 88 & 12 & 0 & 23.9 & 4.58 & 0.2 & 1.0 & $\Delta$ \\
\hline & & & $398 \mathrm{~kg}$ & 72 & 28 & 0 & 27.9 & 4.80 & 0.2 & 1.3 & $\Delta$ \\
\hline & & & $370 \mathrm{~kg}$ & 84 & 16 & 0 & 25.6 & 4.68 & 0.2 & 1.0 & $\Delta$ \\
\hline & & & $317 \mathrm{~kg}$ & 69 & 31 & 0 & 32.2 & 5.01 & 0.3 & 1.2 & $\Delta$ \\
\hline & & & $267 \mathrm{~kg}$ & 74 & 26 & 0 & 30.0 & 4.91 & 0.2 & 1.2 & $\Delta$ \\
\hline & & & $1734 \mathrm{~kg}$ & 78 & 22 & 0 & 27.1 & 4.76 & 0.2 & 1.1 & $\Delta$ \\
\hline \multirow{15}{*}{$\underset{\stackrel{\Xi}{\Xi}}{\stackrel{\mathscr{U}}{U}}$} & \multirow{9}{*}{ Surface } & \multirow{9}{*}{ Surface } & 41 grains & 63 & 34 & 3 & 43.0 & 5.42 & 0.5 & 1.3 & 0.3 \\
\hline & & & 38 grains & 45 & 55 & 0 & 68.6 & 6.10 & 0.6 & 1.1 & 0.4 \\
\hline & & & 43 grains & 51 & 49 & 0 & 60.0 & 5.91 & 0.6 & 1.1 & 0.4 \\
\hline & & & 34 grains & 53 & 47 & 0 & 61.0 & 5.93 & 0.6 & 0.9 & 0.4 \\
\hline & & & 63 grains & 57 & 43 & 0 & 57.3 & 5.84 & 0.4 & 1.0 & 0.3 \\
\hline & & & 33 grains & 55 & 45 & 0 & 59.1 & 5.88 & 0.6 & 0.9 & 0.5 \\
\hline & & & 62 grains & 69 & 31 & 0 & 38.9 & 5.28 & 0.5 & 1.1 & 0.4 \\
\hline & & & 194 grains & 55 & 45 & 0 & 57.7 & 5.84 & 0.4 & 1.2 & 0.2 \\
\hline & & & 508 grains & 56 & 43 & 1 & 56.3 & 5.81 & 0.2 & 1.1 & 0.1 \\
\hline & \multirow{5}{*}{ Surface layer } & \multirow{5}{*}{ Volume } & $430 \mathrm{~kg}$ & 56 & 44 & 0 & 47.2 & 5.56 & 0.3 & 1.2 & $\Delta$ \\
\hline & & & $372 \mathrm{~kg}$ & 63 & 37 & 0 & 37.3 & 5.22 & 0.3 & 1.2 & $\Delta$ \\
\hline & & & $555 \mathrm{~kg}$ & 69 & 31 & 0 & 33.8 & 5.08 & 0.3 & 1.2 & $\Delta$ \\
\hline & & & $310 \mathrm{~kg}$ & 52 & 44 & 4 & 52.5 & 5.71 & 0.3 & 1.3 & $\Delta$ \\
\hline & & & $313 \mathrm{~kg}$ & 63 & 37 & 0 & 38.2 & 5.25 & 0.3 & 1.2 & $\Delta$ \\
\hline & Total & & $1980 \mathrm{~kg}$ & 61 & 38 & 0 & 40.1 & 5.32 & 0.3 & 1.3 & $\Delta$ \\
\hline
\end{tabular}



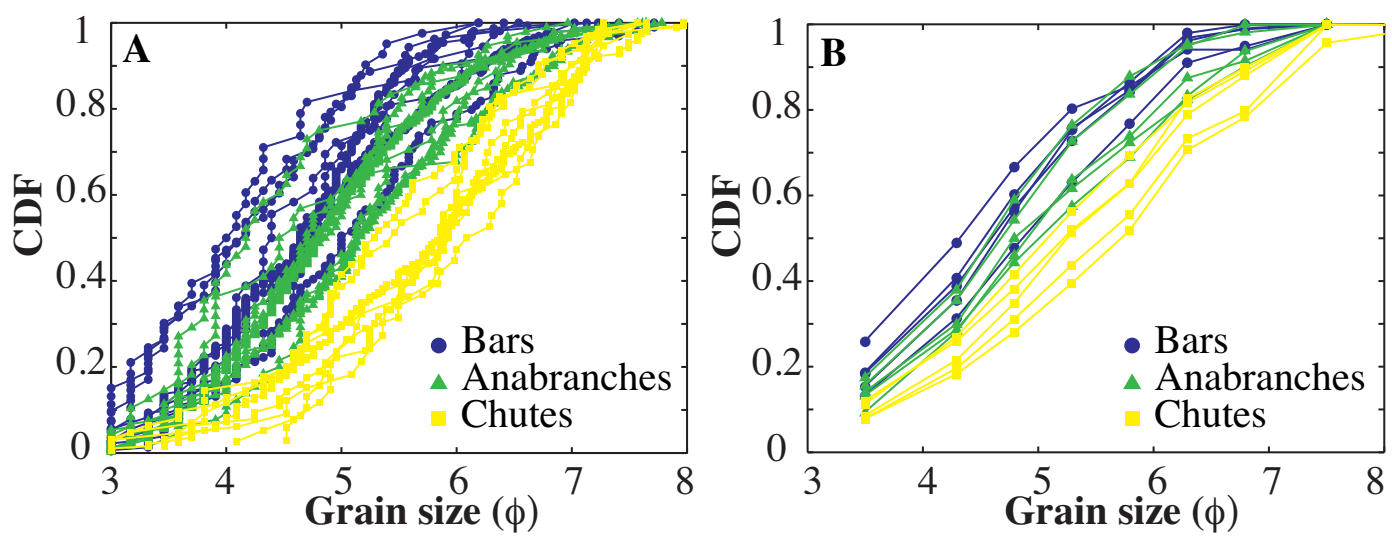

Fig. 5. Individual grain-size distributions of (a) the surface and (b) the surface layer of the sampled elements. Each kind of element is characterized by a range of grain sizes with an overlap between the bars (blue dots) and the anabranches (green triangles) distributions. In contrast, the chute distributions (yellow squares) clearly differ, indicating that chutes are always coarser-grained than anabranches and bars.

Table 2. ANOVA tests on the surface grain-size distributions of the three kinds of morpho-sedimentary element. df is the number of degrees of freedom, SS the sum of square and MS the mean square. $P$ is the probability to get this value $F$ from samples extracted from a single population. The null hypothesis is that there is no difference in the mean values of the grain-size distributions. Chutes are clearly different from anabranches and bars $\left(F>F_{99}\right)$, whereas anabranches and bars cannot be considered as two different populations $\left(F<F_{95}\right)$.

\begin{tabular}{ccccc}
\hline Elements & Variation source & df & SS & MS \\
\hline \multirow{3}{*}{ Bars } & Inter & 1 & 0.41 & 0.41 \\
vs & Intra & 15 & 1.82 & 0.12 \\
Anabranches & Total & 16 & 2.23 & 0.14 \\
& $F$ & $F_{95}$ & $F_{99}$ & $P$ \\
& 3.40 & 4.57 & 8.68 & 0.08 \\
\hline Chutes & Inter & 1 & 3.96 & 3.96 \\
vs & Intra & 14 & 1.41 & 0.10 \\
Anabranches & Total & 15 & 5.37 & 0.36 \\
& $F$ & $F_{95}$ & $F_{99}$ & $P$ \\
& 39.4 & 4.60 & 8.86 & 0.00 \\
\hline Chutes & Inter & 1 & 7.24 & 7.24 \\
vs & Intra & 14 & 1.4 & 0.10 \\
Bars & Total & 15 & 8.73 & 0.53 \\
& $F$ & $F_{95}$ & $F_{99}$ & $P$ \\
& 72.81 & 4.54 & 8.68 & 0.00 \\
\hline
\end{tabular}

To emphasize the average grain-size tendency for each kind of element, the three merged surface GSDs obtained by adding the individual samples can be considered (see section Data acquisition and analysis). According to these merged GSDs, the surface distributions of the anabranches and bars are again quite similar, whereas the chute distribution is different, both in value and shape (Fig. 6a and Table 1). All the quantiles of the chute GSD are coarser than those of the two other elements, as illustrated by the mean diameters. The anabranch and bar $D_{50}$ are close (4.84 and $4.59 \phi$, respectively), whereas the chute $D_{50}$ is much larger $(5.81 \phi)$. The contrast in the shape of the GSD is also striking. For the small grain sizes (from $3 \phi$ to about $5.5 \phi$ ), the chute GSD is flatter than the bar and anabranch GSDs, whereas for the large grain sizes (from $5.5 \phi$ to $8 \phi$ ), this trend is reversed. This result indicates that the surface of the chutes lacks fine grains, or contains more coarse grains, compared to the surface of the two other elements. Indeed, cobbles represent between 11 and $18 \%$ of the anabranch and bar surfaces, whereas they reach $43 \%$ for the chute surface.

Comparison of the merged surface GSDs with the local bulk GSD also provides valuable information. On one hand, the surface GSDs of the anabranches and bars are comparable to the bulk size distribution (Fig. 6a, Table 1). Their $D_{50}$ are not significantly different $(4.59,4.84$ and 4.73 $\phi$, respectively) and their fractions of the different grainsize classes are coherent. The anabranches and bars contain about $85 \%$ pebbles and $15 \%$ cobbles, when the bulk proportions are $78 \%$ and $21 \%$, respectively. The comparison of the bulk quantiles to the element quantiles completes these observations. Except for the high quantiles, the points for the anabranch and bar GSDs nearly fall on the $y=x$ line (Fig. 6b), implying that parameters of the surface size distribution of these two elements are very close to those of the bulk distribution. Therefore, it appears that the surface GSDs of the anabranches and bars correspond to the bulk GSD of the river bed. This result suggests that there is no significant grain sorting between the surface and subsurface grain sizes within these elements.

On the other hand, the chute $D_{50}(5.81 \phi)$ is much larger than the bulk $D_{50}(4.73 \phi)$, as well as the content in cobbles (43\% as against $21 \%$ ) (Fig. 6a, Table 1). On the bulkelement quantile-quantile diagram, the points are aligned, but not on the $y=x$ line (Fig. 6b), implying that even if the bulk 

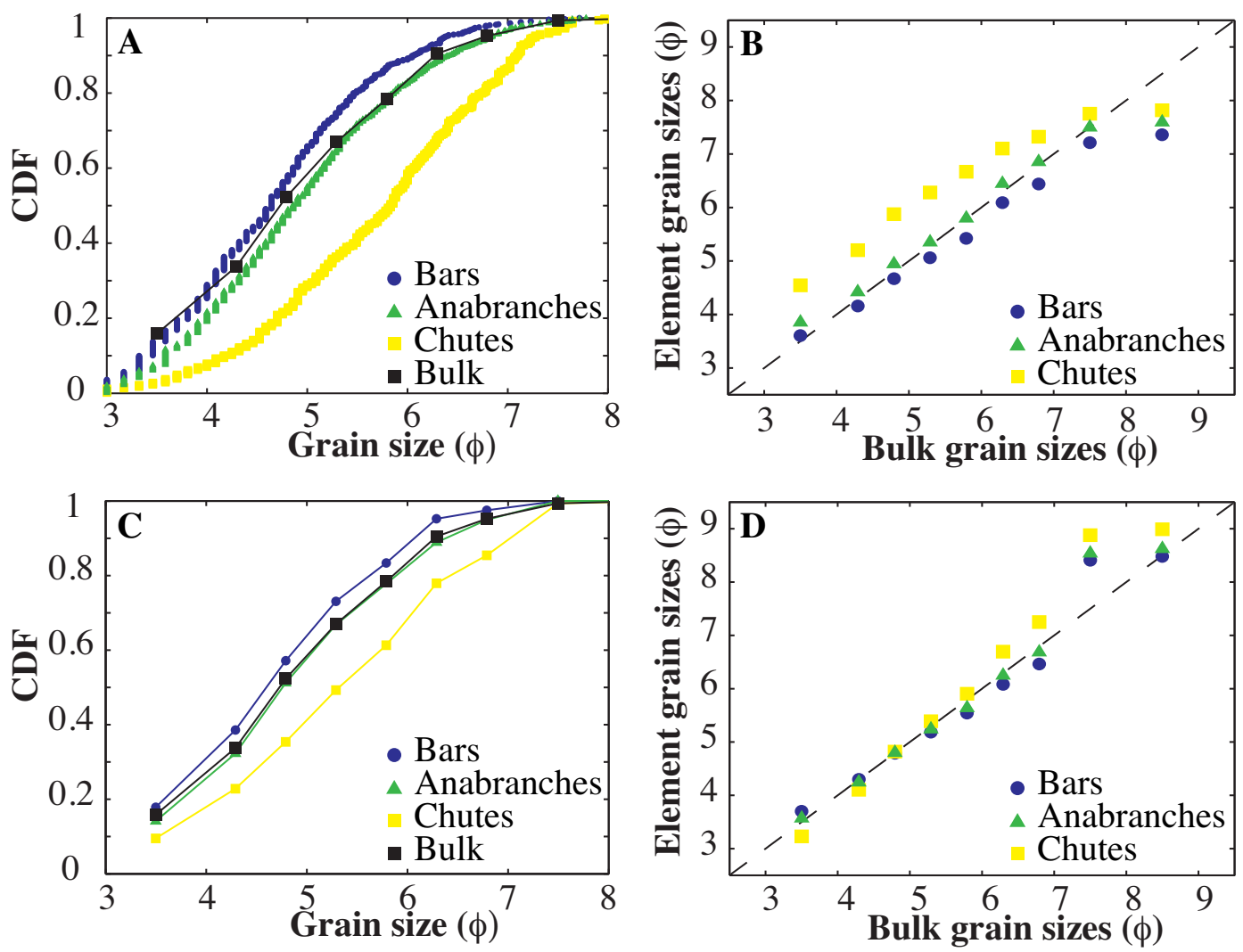

Fig. 6. Merged grain-size distributions of the sampled elements compared to the bulk distribution of the river bed. (a) Grain-size distribution and (b) Q-Q plots for the surface samples. (c) Grain-size distribution and (d) Q-Q plots for the surface-layer samples. The grain-size distributions of the bars (blue dots) and the anabranches (green triangle) are quite similar, both in values and shapes, and compare well with the bulk distribution (black squares). In contrast, the grain-size distributions of the chutes (yellow squares) are clearly different from the anabranch, bar and the bulk distributions. This difference is more marked for the surface material (a and $\mathbf{b})$ than for the surface layer (c and $\mathbf{d}$ ).

and chute distributions are both normally distributed, they have different parameters $D_{50}$ and $\sigma$. The surface GSD of the chutes clearly deviates from the bulk GSD of the river bed. The former lacks fine grains, which indicates a grainsize sorting between the surface and the subsurface at the place of the chutes.

Consequently, in the active threads of the Urumqi River, sediments are sorted into two kinds of patches defined by distinct ranges of grain sizes: (1) the coarse-grained chutes, coarser than the bulk river bed, with many cobbles, and (2) the finer-grained anabranches and bars, consistent with the bulk river bed, with fewer cobbles and more pebbles.

\subsection{Insights from the surface-layer distributions of the morpho-sedimentary elements}

The volumetric samples of the surface layer taken from five chutes, five anabranches and five bars were compared to study the transition between the surface and the subsurface below the grain-size patches. The differences observed between the surface GSDs of the elements also exist between their surface-layer distributions (Fig. 5b and Table 1). The surface-layer GSDs of the chutes is typically coarser than the anabranch and bar ones. Each kind of element is still characterized by a range of distributions with a large overlap for the anabranch and bar grain sizes that are too close to be distinguished, while the chute GSDs are shifted to the right compared to the other ones. Indeed, the anabranch and bar $D_{50}$ range from 4.33 to $5.01 \phi$, whereas the chute $D_{50}$ are between 5.08 to $5.71 \phi$. The results of the ANOVA tests indicate again that the anabranch and bar GSDs belong to one single population, whereas the chute GSDs are from another population (Table 3 ).

The three merged surface-layer GSDs obtained by adding the individual samples also support these observations. All the quantiles of the chute GSDs, as well as the mean diameter, are coarser than those of the two other elements, which are quite similar (Fig. 6c and Table 1). However, if the surface and surface-layer GSDs are similar for the anabranches and bars, they are significantly different for the chutes. For example, the surface and surface-layer $D_{50}$ of the anabranches and bars range from 4.59 to $4.87 \phi$, whereas the 
chute $D_{50}$ are 5.81 and $5.32 \phi$, respectively (Tab. 1). Furthermore, the surface-layer GSD of the chutes does not clearly lack fine grains, contrary to what is observed for the surface distribution (Figs. 6a and 6c).

As for the surface distributions, the surface-layer GSDs of the anabranches and bars are very similar to the local bulk GSD (Fig. 6c, Table 1). Their $D_{50}$ are very close (4.60, 4.76 and $4.73 \phi$, respectively), as well as their fractions of the different grain-size classes. The surface-layer GSDs of the anabranches and bars have parameters consistent with those of the bulk GSD, exactly like their surface distributions (Figs. 6b and 6d). Results are quite different for chutes. Their surface-layer GSD is closer to the bulk GSD than their surface distribution: the surface-layer $D_{50}$ of the chutes (5.32 $\phi)$ is closer to the bulk one $(4.73 \phi)$ than their surface $D_{50}$ $(5.81 \phi)$ (Fig. 6c and Table 1).

Consequently, the surface and surface-layer GSDs of the anabranches and bars are equivalent to the bulk GSD. This supports the lack of a grain-size sorting from the surface to the subsurface at the place of the bar-anabranch patches. For these patches, the surface GSD seems to be the exact surface expression of the surface-layer distribution, which is consistent with the bulk GSD. On the other hand, the surface GSD of the chutes is clearly coarser-grained than the local surfacelayer GSD, which is itself coarser than the bulk distribution of the river bed. This trend demonstrates a grain-size sorting from the surface to the subsurface below the chute patches. At these locations, there is a clear disconnection between the first layer of grains, building up the surface, and the grains lying at depth. Actually, the shallow trenches dug for the surface-layer samplings reveal that, at chute places, the river bed is composed of one coarse-grained layer lying on the surface with finer-grained sediments below (Fig. 7a). As expected, the surface layer of anabranches and bars is much more homogeneous (Fig. 7b), which strengthens the distinction established between the two kinds of patches.

\section{Discussion}

In the shallow braided gravel-bed Urumqi River, sediments are sorted into two kinds of grain-size patches: the coarsegrained chutes and the finer-grained anabranches and bars. Chutes are typically located at flow constrictions where the flow velocity and the grain transport increases (Church and Gilbert, 1975; Davoren and Mosley, 1986; Ashmore et al., 1992; Ashworth et al., 1992a, b; Ashworth, 1996). They may correspond to the areas of erosion identified by topographic surveys in braided streams (e.g., Wheaton et al., 2010; Ashmore et al., 2011; Limare et al., 2011). Below these chutes, a vertical grain-size sorting occurs from the surface to the subsurface of the river bed. Indeed, these patches are characterized by a coarse top layer, which can be interpreted as a local active armour. This grain-size structure possibly implies that chute patches correspond to a single layer of coarse grains
Table 3. ANOVA tests on the surface-layer grain-size distributions of the three kinds of morpho-sedimentary elements. df is the number of degrees of freedom, SS the sum of square and MS the mean square. $P$ is the probability to get this value $F$ from samples extracted from a single population. The null hypothesis is that there is no difference in the mean values of the grain-size distributions. Chutes are clearly different from anabranches and bars $\left(F>F_{99}\right)$, whereas anabranches and bars cannot be considered as two different populations $\left(F<F_{95}\right)$.

\begin{tabular}{ccccc}
\hline Elements & Variation source & df & SS & MS \\
\hline \multirow{3}{*}{ Bars } & Inter & 1 & 0.11 & 0.11 \\
vs & Intra & 8 & 0.27 & 0.03 \\
Anabranches & Total & 9 & 0.37 & 0.04 \\
& $F$ & $F_{95}$ & $F_{99}$ & $P$ \\
& 3.2 & 5.32 & 11.26 & 0.11 \\
\hline Chutes & Inter & 1 & 0.81 & 0.81 \\
vs & Intra & 8 & 0.39 & 0.05 \\
Anabranches & Total & 9 & 1.20 & 0.13 \\
& $F$ & $F_{95}$ & $F_{99}$ & $P$ \\
& 16.48 & 5.32 & 11.26 & 0.00 \\
\hline Chutes & Inter & 1 & 1.50 & 1.50 \\
vs & Intra & 8 & 0.42 & 0.05 \\
Bars & Total & 9 & 1.92 & 0.21 \\
& $F$ & $F_{95}$ & $F_{99}$ & $P$ \\
& 28.59 & 5.32 & 11.26 & 0.00 \\
\hline
\end{tabular}

with no extension in depth. If so, the surface-layer samples taken at chute places are not made of chute grains only, but of a mix of chute grains and what lies below. In contrast, anabranches and bars usually develop at flow expansions, downstream of the chutes, where the flow velocity and grain transport decrease (Davoren and Mosley, 1986; Ashmore et al., 1992; Ashworth, 1996). These patches correspond to areas of deposition. Their grain size is finer and much more homogeneous in depth than the chute sizes, without any vertical sorting. Surprisingly, the local bulk GSD of the Urumqi River does not correspond to the addition of the grain sizes of the chute and bar-anabranch patches. If the latter are the exact surface expression of the bulk river bed, the former are different. However, these patches must be paired and found in equal numbers in the stream. Therefore, the discrepancy between the chute and bulk GSDs also indicates that, in addition to vertical sorting, the chute deposits must be much more limited than the bar-anabranch deposits in term of spatial extension and volume, or that the distribution of coarse grains does not affect much the bulk size distribution (Ashworth et al., 1992b). In other words, the river bed seems to be mainly composed by the grains deposited in bar-anabranch patches. This issue should be tested on the field. At present, the available satellite or photographic data do not enable the characterization of the surface extension of the chutes compared to the extension of the unit bars-anabranches. Microscale 

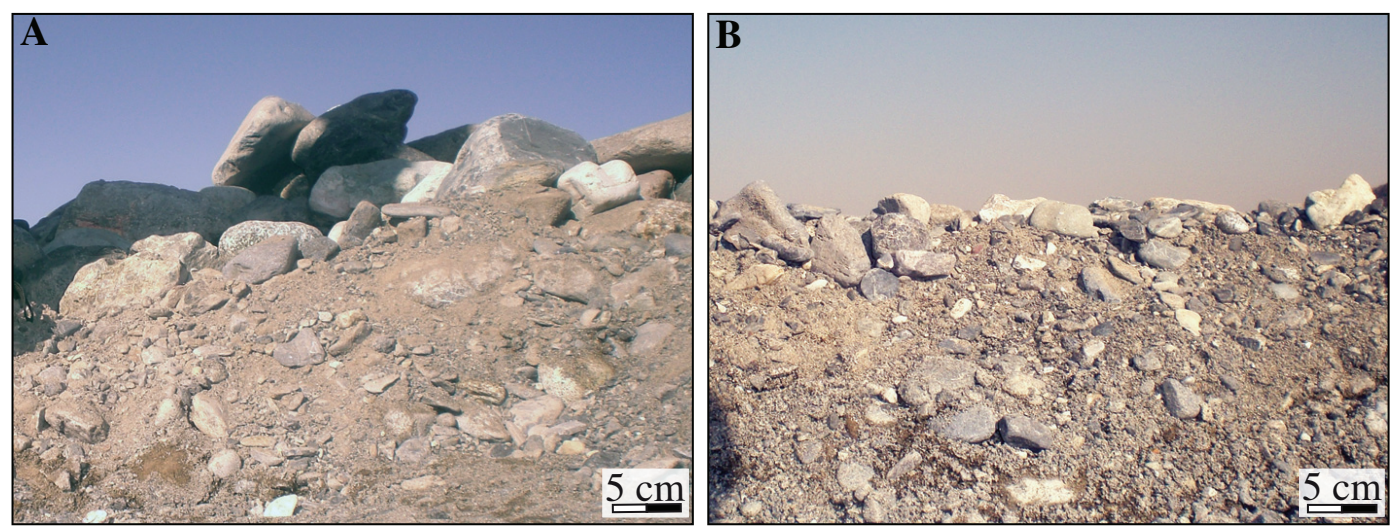

Fig. 7. View of a wall of trenches dug in (a) a chute and (b) a bar. The chute is clearly made up of one coarse layer with no vertical extension, whereas the bar deposits are more homogeneous in depth.

experiments using two different grain sizes could be used to test this explanation.

Others grain-size studies have focused on shallow braided rivers. According to their hydrological regime, these rivers seem to divide into two categories: ephemeral or perennial. Ephemeral streams are rivers flowing only a few days per year during flash floods. In these rivers, unit bars are coarsergrained than thalwegs (Laronne et al., 1994; Hassan, 2005; Laronne and Shlomi, 2007). This could be related to their rapid flow recession that prevents any reworking of the fine grains brought within thalwegs (Hassan et al., 2006). On the other hand, perennial rivers usually flow all the year long. Flowing all year-long, with a marked high-flow from May to September, the Urumqi River can be considered as a perennial stream. In terms of grain size, its unit bars are finergrained than its thalwegs, as other streams with a strong seasonality (Smith, 1974; Ashworth et al., 1992b). However, this work shows that the chute and anabranch thalwegs do not share the same grain-size range, the anabranches being closer to the unit bars. This questions the relevancy of the topography as a selection criterion for the location of grain-size studies in shallow braided gravel-bed rivers.

Besides this aspect of grain-size patches, the shallow braided gravel-bed rivers, where it has been investigated, are not armoured (Laronne et al., 1994; Laronne and Shlomi, 2007). Even if the chute patches of the Urumqi River present an active armour, they do not build an extensive coarse layer on the top of the river bed. Therefore, the Urumqi River is not armoured either. The absence of a well-developed armoured layer indicates that the equal mobility theory developed to understand and predict the transport of sediment mixtures may not be adequate for such stream. This theory requires sediments to be sorted into an extensive coarse-grained surface and a finer-grained subsurface layer in order to make the coarse grains more available for transport than the fine ones (Parker and Klingeman, 1982; Andrews, 1987; Parker and Toro-Escobar, 2002). Nevertheless, a high sediment supply prevents the formation of this vertical sorting (Dietrich et al., 1989; Gran et al., 2006; Hassan et al., 2006). This could explain why those braided rivers, either ephemeral or not, are not armoured, which is in agreement with a recent synthesis suggesting that multiple-thread gravel-bed streams have higher sediment supplies than single-thread streams (Métivier and Barrier, 2012).

All those observations are also in good agreement with the experiments of Gardner and Ashmore (2011). They used a Froude-scaled physical model to simulate a coarse-grained braided river with a bimodal sediment distribution. They mapped the thickness of the river-bed active layer during the experiments, as well as the grain-size texture of its basal and top surfaces. It appears that the experimental river bed is made of grain-size patches and that the grain-size distributions are the same at its bottom and its top. The authors even suggest that there is no vertical sorting at all in this layer that is active during flood (about $20 D_{50}$ for their experiments). Scaled to $D_{50}$ of the sample extracted from the $1 \mathrm{~m}$ deep trench, the typical thickness of the Urumqi active layer should be about $60 \mathrm{~cm}$, which is consistent with the homogeneity in the depth of the river bed studied here. This suggests that in spite of a spatial sorting at the bed surface, the layer of hydro-sedimentary activity is the same in granulometry than the river deposit on a whole.

Eventually, this kind of grain-size organization (two grainsize patches with no general armouring) could be typical of shallow braided gravel-bed rivers (defined here as rivers with a decimetric to metric water depth) where sediments are deposited into a limited number of morpho-sedimentary elements (see the facies model \#2 of Miall 1985, 1996). Other types of braided streams, such as deep braided gravel-bed rivers (defined as rivers with a metric to pluri-metric water depth) (facies model \#3 of Miall 1985, 1996), may have a more complicated grain-size organization. For example, they often present bedforms with avalanche slip faces, which can produce a complex upward and downstream sorting within 
bars (Bluck, 1976; Hein and Walker, 1977; Ashmore, 1982; Paola, 1989; Lunt and Bridge, 2004; Rice and Church, 2010). Therefore, it would be interesting to investigate the grain-size patchiness in such streams and to compare it with the framework defined here for shallow braided gravel-bed rivers.

\section{Conclusions}

The careful study reported here brings new insights into the grain-size sampling and patchiness of a shallow braided gravel-bed stream. In the active threads of the Urumqi River, the three unitary morpho-sedimentary elements (chutes, anabranches and bars) typical of such streams can be identified. The surface material and surface layer of these elements were sampled respectively by surface counts and volumetric samplings, in order to look at their grain-size characteristics.

On average, the chute grain size is coarser than the anabranch grain size, which is itself a little bit coarser than the bar grain size. However, if the difference between the chutes and the two other elements is significant, the grainsize range of the anabranches and bars are too close to be distinguished. Consequently, the three unitary morphosedimentary elements of the Urumqi river bed only build two kinds of grain-size patches defined by distinct ranges of grain sizes: (1) coarse-grained chutes with many cobbles and (2) finer-grained anabranches and bars with less cobbles and more pebbles. These patches may correspond respectively to the areas of erosion and deposition identified by topographic surveys in braided chive threads.

In depth, these two types of patches present a different structure. Below the chutes, vertical grain-size sorting occurs. At their place, one coarse-grained top layer, which can be interpreted as a local active armour, lies on finer deposits. In contrast, the grain size of the bar-anabranch patches is finer and much more homogeneous in depth than the chute patch, without any vertical sorting from the surface to the subsurface of the river bed.

These chute and bar-anabranch patches, which are features of lateral and vertical sorting associated to the dynamics objects that build braided patterns, may be typical of shallow gravel-bed rivers. The understanding of their dynamics could be improved by considering their characteristics in both models and field studies based on data collected with an adequate sampling strategy. At the reach scale, grain-size studies should be performed with grids or trenches larger than the characteristic length or depth of the patches. At the patch scale, small grids can be used, but the topography should not be a criterion to choose their location. Indeed, this work shows that sorting seems not related to the morphology of the bed (concave for the chute and anabranch thalwegs vs. convex for the bars), but rather to the local sediment transport processes (erosional vs. depositional patches). The patch characteristics quantified by such a sampling strategy could then be considered in future works on sorting processes and their geomorphologic and stratigraphic results.

Acknowledgements. This work is dedicated to the memory of Baisheng Ye who died on August 22, 2012 in a car accident during a field trip in Tibet. We could never have carried out this study without his help. This work was funded by the French CNRS-INSU. The authors thank Sara Mullin for its editorial assistance. Finally, we are grateful to reviewers Peter Ahsmore and John Pitlick for their critical and constructive comments and suggestions. This is IPGP contribution 3176.

Edited by: Z. Dong

Reviewed by: J. Pitlick and P. Ashmore

\section{References}

Andrews, E. D. and Parker, G.: Sediment transport In Gravel-bed rivers, chap. Formation of a coarse surface layer as a response to gravel mobility, 269-325, John Wiley \& Sons Ltd., 1987.

Ashmore, P. E.: Laboratory modelling of gravel braided stream morphology, Earth Surf. Proc. Land., 7, 201-225, 1982.

Ashmore, P. E., Ferguson, R. I., Prestegaard, K. L., Ashworth, P. J., and Paola, C.: Secondary flow in anabranch confluences of a braided, gravel-bed stream, Earth Surf. Proc. Land., 17, 299-311, 1992.

Ashmore, P. E., Bertoldi, W., and Gardner, J.: Active width of gravel bed braided rivers, Earth Surf. Proc. Land., 36, 1510-1521, 2011.

Ashmore, P. E.: Treatise on Geomorphology, chap. Morphology and Dynamics of Braided Rivers, 289-312, San Diego, Academic Press, 2013.

Ashworth, P. J.: Mid-channel bar growth and its relationship to local flow strength and direction, Earth Surf. Proc. Land., 21, 103-123, 1996.

Ashworth, P. J. and Ferguson, R. I.: Interrelationships of channels processes, changes and sediments in a proglacial braided river, Geogr. Ann. A, 68, 361-371, 1986.

Ashworth, P. J., Ferguson, R. I., Ashmore, P. E., Paola, C., Powell, D. M., and Prestegaard, K. L.: Measurements in a Braided River Chute and Lobe 2. Sorting of Bed-Load During Entrainement, Transport, and Deposition, Water Resour. Res., 28, 1887-1896, 1992a.

Ashworth, P. J., Ferguson, R. I., and Powell, M. D.: Dynamics of gravel-bed rivers, chap. Bedload transport and sorting in braided channels, 497-515, John Wiley \& Sons Ltd., 1992b.

Bluck, B. J.: Sedimentation in the meandering River Endrick, Scot. J. Geol., 7, 93-138, 1971.

Bluck, B. J.: Structure and directional properties of some valley sandur deposits in southern Iceland, Sedimentology, 21, 533-554, 1974.

Bluck, B. J.: Sedimentation in some Scottish rivers of low sinuosity, Transactions Royal Society of Edinburgh, 69, 425-455, 1976.

Bluck, B. J.: Gravel-bed Rivers: Fluvial Processes, Engineering and Management, chap. Texture of gravel bars in braided streams, 339-355, John Willey \& Sons, 1982.

Bluck, B. J.: River channels: environment and process, chap. Bed forms and clast size changes in gravel-bed rivers, 159-178, 17, 
Institute of British Geographers Special Publications, Blackwell, 1987.

Bunte, K. and Abt, S. R.: Sampling surface and subsurface particlesize distributions in wadable gravel-and cobble-bed streams for analyses in sediment transport, hydraulics, and streambed monitoring, Gen. Tech. Rep. RMRS-GTR-74, 2001.

Church, M. and Jones, D.: Gravel-bed Rivers: Fluvial Processes, Engineering and Management, chap. Channel bars in gravel-bed rivers, 281-338, John Willey \& Sons, 1982.

Church, M. and Gilbert, R.: Glaciofluvial and glaciolacutrine sedimentation, chap. Proglacial fluvial and lacustrine environments, 22-100, Special Publications of the Society of Economic Paleontologists and Mineralogists, 1975.

Church, M. A., McLean, D. G., and Wolcott, J. F.: Sediments transport in Gravel Bed Rivers, chap. River Bed Gravels: Sampling and Analysis, 43-88, John Wiley \& Sons, New York, 1987.

Davoren, A. and Mosley, M. P.: Observations of Bedload Movement, Bar Development and Sediment Supply in the braided Ohau River, Earth Surf. Proc. Land., 11, 643-652, 1986.

Dietrich, W. E., Kirchner, J. W., Ikeda, H., and Iseya, F.: Sediment supply and the development of the coarse surface-layer in gravelbedded rivers, Nature, 340, 215-217, 1989.

Diplas, P. and Fripp, J. B.: Properties of Various Sediment Sampling Procedures, Journal of Hydraulic Engineering-ASCE, 118, 955970, 1992.

Ferguson, R. I., Prestegaard, K. L., and Ashworth, P. J.: Influence of sand on hydraulics and gravel transport in a braided gravel bed river, Water Resour. Res., 25, 635-643, 1989.

Garcia, C., Laronne, J. B., and Sala, M.: Variable source areas of bedload in a gravel-bed stream, J. Sediment. Res., 69, 27-31, 1999.

Gardner, T. J. and Ashmore, P. E.: Geometry and grain-size charateristics of the basal surface of a braided river deposit, Geology, 39, 247-250, 2011.

Gran, K. B., Montgomery, D. R., and Sutherland, D. G.: Channel bed evolution and sediment transport under declining sand inputs, Water Resour. Res., 42, 2006.

Hassan, M. A.: Characteristics of gravel bars in ephemeral streannis, J. Sediment. Res., 75, 29-42, 2005.

Hassan, M. A., Egozi, R., and Parker, G.: Experiments on the effect of hydrograph characteristics on vertical grain sorting in gravel bed rivers, Water Resour. Res., 42, 2006.

Hein, F. J. and Walker, R. G.: Bar evolution and development of stratification in the gravelly, braided, Kicking Horse River, British Columbia, Can. J. Earth Sci., 14, 562-570, 1977.

Kellerhalls, R. and Bray, D. I.: Sampling Procedures for Coarse Fluvial Sediments, Journal of the Hydraulics Division ASCE, 97, 1165-1180, 1971.

Kondolf, G. M. and Wolman, M. G.: The sizes of salmonid spawing gravels, Water Resour. Res., 29, 2275-2285, 1993.

Lane, S. N., Reid, I., Yitshak, Y., and Frostick, L. E.: Estimation of erosion and deposition volumes in a large, gravel-bed, braided river using synoptic remote sensing, Earth Surface Proc. Land., 28, 249-271, 2003.

Laronne, J. B. and Shlomi, Y.: Depositional character and preservation potential of coarse-grained sediments deposited by flood events in hyper-arid braided channels in the Rift Valley, Arava, Israel, Sediment. Geol., 195, 21-37, 2007.
Laronne, J. B., Reid, I., Yitshak, Y., and Frostick, L. E.: The nonlayering of gravel streambeds under ephemeral flood regimes, J. Hydrol., 159, 353-363, 1994.

Leopold, L. B., Wolman, M. G., and Miller, J. P.: Fluvial processes in geomorphology, Freeman, 1964.

Limare, A., Tal, M., Reitz, M. D., Lajeunesse, E., and Métivier, F.: Optical method for measuring bed topography and flow depth in an experimental flume, Solid Earth, 2, 143-154, doi:10.5194/se2-143-2011, 2011.

Lisle, T. E. and Madej, M. A.: Dynamics of gravel-bed rivers, chap. Spatial variation in armouring in a channel with high sediment supply, John Willey \& Sons, 1992.

Liu, Y., Métivier, F., Lajeunesse, E., Lancien, P., Narteau, C., and Meunier, P.: Measuring bed load in gravel bed mountain rivers: averaging methods and sampling strategies, Geodynam. Ac., 21, 81-92, 2008.

Liu, Y., Métivier, F., Gaillardet, J., Ye, B., Meunier, P., Narteau, C., Lajeunesse, E., Han, T., and Malverti, L.: Erosion rates deduced from seasonal mass balance along the upper Urumqi River in Tianshan, Solid Earth, 2, 283-301, doi:10.5194/se-2-283-2011, 2011.

Lunt, I. A. and Bridge, J. S.: Evolution and deposits of a gravelly braid bar, Sagavanirktok River, Alaska, Sedimentology, 51, 415432, 2004.

Métivier, F. and Barrier, L.: Gravel-Bed Rivers: Processes, Tools, Environments, chap. Alluvial landscape evolution: what do we know about metamorphosis of gravel bed meandering and braided streams, 474-501, John Wiley \& Sons, New York, 2012.

Métivier and F. Meunier, P.: Input and output mass fluxes correlations in an experimental braided stream. Implications on the dynamics of bed load transport, J. Hydrol., 271, 22-38, 2003.

Miall, A. D.: Architectural-elements analysis: a new method of facies analysis applied to fluvial deposits, Earth-Sci. Rev., 22, 261308, 1985.

Miall, A. D.: The Geology of Fluvial Deposits, Springer, Berlin,1996.

Milne, J. A.: Bed-material size and the riffle-pool sequence, Sedimentol., 29, 267-278, 1982.

Naot, D.: Response of channel flow to roughness heterogeneity, Journal of Hydraulic Engineering-ASCE, 110, 1568-1587, 1984.

Nemec, W. and Postma, G.: Alluvial Sedimentation, 235-276, 17, Int. Assoc. Sedimentolo. Spec. Public., 1993.

Paola, C.: Topographic sorting, EOS Transaction American Geophysical Union, 70, 332, 1989.

Paola, C. and Seal, R.: Grain-size patchiness as a cause of selective deposition and downstream fining, Water Resour. Res., 31, 1395 1407, 1995.

Parker, G. and Klingeman, P. C.: On why gravel bed streams are paved, Water Resour. Res., 18, 1409-1423, 1982.

Parker, G. and Toro-Escobar, C. M.: Equal mobility of gravel in streams: The remains of the day, Water Resour. Res., 38, 2002.

Rice, S. and Church, M.: Sampling surficial fluvial gravels the precision of size distribution percentile estimates, J. Sediment. Res., 66, 654-665, 1996.

Rice, S. and Church, M.: Grain-size Sorting within River Bars in Relation to Downstream Fining Along a Wandering Channel, Sedimentol., 57, 232-251, 2010. 
Robert, A., Roy, A. G., and Deserres, B.: Changes in velocity profiles at roughness transitions in coarse-grained channels, Sedimentol., 39, 725-735, 1992.

Sambrook Smith, G. H. and Ferguson, R. I.: The gravel-sand transition: Flume study of channel response to reduced slope, Geomorphol., 16, 147-159, 1996.

Seal, R. and Paola, C.: Observations of Downstream Fining on the North Fork Toutle River near Mount St Helens, Washington, Water Resources Research, 31, 1409-1419, 1995.

Smith, N. D.: Sedimentology and bar formation in upperkickinghorse-river, a braided outwash stream, J. Geol., 82, 205223, 1974.

Southard, J. B., Smith, N. D., and Kuhnle, R. A.: Sedimentology of gravels and conglomerates., chap. Chutes and lobes: Newly identified elements of braiding in shallow gravelly streams, 5159, 10, Can. Soc. Petrol. Geol., 1984.

Steel, R. J. and Thompson, D. B.: Structures and textures in triassic braided stream conglomerates (bunter pebble beds) in the sherwood sandstone group, north Staffordshire, England, Sedimentol., 30, 341-367, 1983.

Sutherland, A. J.: Sediment transport In Gravel-bed rivers, chap. Armouring processes, 243-267, John Wiley \& Sons Ltd., 1987.
Vericat, D., Batalla, R. J., and Gibbins, C. N.: Sediment entrainment and depletion from patches of fine material in a gravel-bed river, Water Resour. Res., 44, 2008.

Wentworth, C. K.: A scale of grade and class terms for clastic sediments, J. Geol., 1922.

Wheaton, J., Brasington, J., Darby, S., and Sear, D.: Accounting for uncertainty in DEMs from repeat topographic surveys: improved sediment budgets, Earth Surf. Proc. Land., 35, 136-156, 2010.

Wiens, J. A.: Populations responses to patchy environments, Annu. Rev. Ecol. Syst., 7, 81-120, 1976.

Wilcock, P. and McArdell, B.: Surface-based fractional transport rates: Mobilization thresholds and partial transport of a sandgravel sediment, Water Resour. Res., 29, 1297-1312, 1993.

Wolman, M. G.: A method for sampling coarse river-bed material, Am. Geophys. Union Tr., 35, 951-956, 1954.

Zhou, L., Yang, F., and Shao, X.: River hydrology and water resources in Xinjiang, Urumqi (in chinese), Xinjiang Science and Technology Press, 1999.

Zhou, S. Z., Jiao, K. Q., Zhao, J. D., Zhang, S. Q., Cui, J. X., and $\mathrm{Xu}, \mathrm{L}$. B.: Geomorphology of the Urumqi River Valley and the uplift of the Tianshan Mountains in Quaternary, Science en China Series D: Earth Sci., 45, 961-968, 2002. 